\title{
The Usage of Backscattered Electrons in Scanning Electron Microscopy
}

Pavel Kejzlar ${ }^{1}$, Martin Švec ${ }^{2}$, Eva Macajová

${ }^{1}$ Institute for Nanomaterials, Advanced Technologies and Innovation, Technical University of Liberec. Studentska 1402/2, 46117 Liberec. Czech Republic. E-mail: pavel.kejzlar@tul.cz

${ }^{2}$ Department of Materials Science, Technical University of Liberec, Studentska 1402/2, Liberec, Czech Republic. E-mail: martin.svec@tul.cz; eva.macajova@tul.cz

Secondary and backscaterred electrons are the most common signals used for imaging in the scanning electron microscopy. Generally, SE are used to obtain topographical contrast while BSE show differences in chemical composition (so called Z-contrast). The aim of the present work is to show possibilities and techniques to obtain not-socommon information using BSE, as e.g. orientation contrast, residual stress, different allotropic modifications, etc.

Keywords: Scanning Electron Microscopy, BSE, Structure.

\section{Acknowledgement}

The results of this project LO1201 were obtained with co-funding from the Ministry of Education, Youth and Sports as part of targeted support from the "Národní program udržitelnosti I" programme.

\section{References}

[1] HAFNER, B. Scanning Electron Microscopy Primer. Available from: http://www.charfac.umn.edu/instruments/sem_primer.pdf

[2] LIAO, Yougui. (2007). Practical Electron Microscopy and Database - An Online Book [online]. Second Edition. 2007 [cit. 2014-06-04]. Available from: http://www.globalsino.com/EM/

[3] KRUMEICH, F. Properties of Electrons, their Interactions with Matter and Applications in Electron Microscopy. Available from: http://www.microscopy.ethz.ch/downloads/Interactions.pdf

[4] KACZMAREK, D. (1998). Backscattered electrons topographic mode problems in the scanning electron microscope. Scanning Microscopy Vol. 12, No. 1, 1998, p. 161-169.

[5] JAKSH, H. (2008). Strain related contrast mechanisms in crystaline materials. In: EMC 2008: 14th European microscopy Congress 1-5 September 2008, Aachen Germany; Volume 1: Instrumentation and methods. 1st ed. New York: Springer, 2008. ISBN 9783540851547

[6] JAKSH, H. (2009). Low Loss BSE Imaging in FE-SEM. In: Microscopy Conference 2009 in Graz, Austria, Verlag der TU Graz 2009, DOI: 10.3217/978-3-85125-062-6-143

[7] JAKSH, H. (2010). Low Loss-BSE Electrons and Their Contrast in FE-SEM. In: International Microscopy Conference 2010, Rio de Janeiro, Brasil. 